\title{
A high neutrophil-to-lymphocyte ratio is a poor prognostic factor for castration- resistant prostate cancer patients who undergo abiraterone acetate or enzalutamide treatment
}

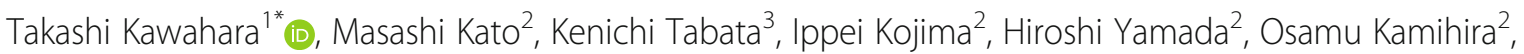 \\ Hideyasu Tsumura ${ }^{3}$, Masatsugu Iwamura ${ }^{3}$, Hiroji Uemura ${ }^{1}$ and Yasuhide Miyoshi ${ }^{1}$
}

\begin{abstract}
Background: Inflammatory cytokine markers, including the neutrophil-to-lymphocyte ratio (NLR), monocytelymphocyte ratio, and platelet-to-lymphocyte ratio, play important roles as prognostic markers in several solid malignancies, including prostate cancer. We previously reported the NLR as a poor prognostic marker in bladder cancer, upper-urothelial carcinoma, adrenocortical carcinoma, penile cancer, and prostate cancer. This study examined the importance of the NLR as a prognostic marker for castration-resistant prostate cancer (CRPC) patients who received abiraterone acetate or enzalutamide.

Methods: A total of 805 prostate cancer patients developed in CRPC status were enrolled in this study. Of these patients, 449 received abiraterone acetate (ABI; 188 cases) or enzalutamide (ENZ; 261 cases) treatment, and the pre-treatment NLR values of these patients were obtained. We investigated the prognosis in those with higher and lower NLR values.

Results: The median NLR was 2.90, and a receiver operating characteristics analysis suggested a candidate cut-off point of 3.02. The median overall survival (OS) was 17.3 months in the higher NLR group ( $\geq 3.02)$ and 27.3 months in the lower NLR group $(<3.02)(p<0.0001)$. This trend was also observed in both the ABI and ENZ groups (ABI: 29.3 vs. 15.1 months; ENZ: NR vs. 19.5 months; $p<0.0001$ and $<0.0001$, respectively). A multivariate analysis revealed that a higher NLR was an independent risk factor. The NLR value was thus shown to be correlated with the prostate cancer progression.
\end{abstract}

Conclusions: A higher NLR was associated with a poorer OS for CRPC patients who received ABI or ENZ. The NLR was positively correlated with prostate cancer progression.

Keywords: The NLR, Abiraterone acetate, Enzalutamide

\footnotetext{
*Correspondence: takashi_tk2001@yahoo.co.jp; takashi_tk2001@yokohamacu.ac.jp

'Departments of Urology and Renal Transplantation, Yokohama City University Medical Center, Yokohama 2320024, Japan

Full list of author information is available at the end of the article
}

\section{Background}

Some inflammatory cytokine markers, including the neutrophil-to-lymphocyte ratio (NLR), monocytelymphocyte ratio (MLR), and platelet-to-lymphocyte ratio, play important roles as prognostic markers in certain solid malignancies, including prostate cancer [1]. We previously reported the NLR to be a poor prognostic

C The Author(s). 2020 Open Access This article is licensed under a Creative Commons Attribution 4.0 International License, which permits use, sharing, adaptation, distribution and reproduction in any medium or format, as long as you give appropriate credit to the original author(s) and the source, provide a link to the Creative Commons licence, and indicate if changes were made. The images or other third party material in this article are included in the article's Creative Commons licence, unless indicated otherwise in a credit line to the material. If material is not included in the article's Creative Commons licence and your intended use is not permitted by statutory regulation or exceeds the permitted use, you will need to obtain permission directly from the copyright holder. To view a copy of this licence, visit http://creativecommons.org/licenses/by/4.0/. The Creative Commons Public Domain Dedication waiver (http://creativecommons.org/publicdomain/zero/1.0/) applies to the data made available in this article, unless otherwise stated in a credit line to the data. 
marker in bladder cancer, upper-urothelial carcinoma, penile cancer, and prostate cancer [2-9]. In prostate cancer, the higher NLR group showed a higher incidence of prostate cancer among patients whose PSA was 4-10 $\mathrm{ng} / \mathrm{ml}$. A higher NLR was also associated with a poorer overall survival (OS) in metastatic hormone-sensitive prostate cancer (mHSPC) and castration-resistant prostate cancer (CRPC) patients who underwent docetaxel or cabazitaxel systemic chemotherapy $[3-7,10,11]$. However, there have been no reports on the NLR and prognosis of CRPC patients who received abiraterone acetate (ABI) and enzalutamide (ENZ). A recent clinical trial revealed the efficacy of ABI, ENZ, Radium-223 (Ra223), and cabazitaxel in addition to docetaxel chemotherapy in metastatic castration-resistant prostate cancer (mCPRC) patients [12-14]. In the next few years, poly (ADP-ribose) polymerase (PARP) inhibitors and immune-checkpoint inhibitors are expected to be used in clinical practice to similar ends $[15,16]$. With widespread medication choices now available, clinicians should take care to select the most appropriate medicine in order not to lose their chance to administer the best therapy possible to a patient. Predicting the prognosis is thus important, because a lack of biomarker to predict the efficacy of each mCRPC treatment. NLR is easily calculated using complete blood cell counts (CBCs) which was widely measured in daily clinical practices. Thus, previous data was easily obtained in each patients in each prostate cancer progression stage. And no additional cost is required.

The present study examined the utility of the NLR as a prognostic marker for CRPC patients who received $\mathrm{ABI}$ and/or ENZ.

\section{Methods \\ Patients}

A total of 805 prostate cancer patients who developed CRPC in Yokohama City University, Kitasato University, Nagoya University, and affiliated hospitals were enrolled in this study. Of these patients, 449 received ABI or ENZ, and the pre-treatment NLR values of these patients were obtained (Table 1). All patients received initial androgen deprivation therapy or combined androgen blockade treatment and were refractory to each treatment. The definition of CRPC was set by the Prostate Cancer Working Group 2 [17]. The patients who received both $\mathrm{ABI}$ and ENZ were classified as the first-line treatment group.

Table 1 Patients' characteristics

\begin{tabular}{|c|c|c|c|}
\hline \multirow[b]{2}{*}{ Variables } & \multicolumn{2}{|c|}{ n (\%) or median (mean +/- SD) } & \multirow[b]{2}{*}{$p$ value } \\
\hline & $\overline{A B I}(n: 188)$ & ENZ(n:261) & \\
\hline \multicolumn{4}{|l|}{ Age } \\
\hline$>75.6$ years & $105(55.9 \%)$ & $120(46.0 \%)$ & \multirow[t]{2}{*}{0.039} \\
\hline$\leq 75.6$ years & $83(44.1 \% 9$ & $141(54.0 \%)$ & \\
\hline \multicolumn{4}{|l|}{ Initial distant Metastasis } \\
\hline Yes & $87(46.3 \%)$ & $157(60.2 \%)$ & \multirow[t]{3}{*}{0.248} \\
\hline No & $65(34.6 \%)$ & 99 (37.9\%) & \\
\hline Unknown & $36(19.1 \%)$ & $5(1.9 \%)$ & \\
\hline Initial PSA (ng/mL) & $110(616.2+/-1467.7)$ & $100(648.1+/-1534.9)$ & $<0.001$ \\
\hline \multicolumn{4}{|l|}{ Gleason Score } \\
\hline$\geq 8$ & $93(49.5 \%)$ & $121(46.4 \%)$ & \multirow[t]{2}{*}{0.515} \\
\hline$<8$ & $95(50.5 \%)$ & $140(53.6 \%)$ & \\
\hline Pre ABI/ENZ PSA (ng/mL) & $26.0(189.8+/-595.6)$ & $38.8(233.3+/-737.5)$ & $<0.001$ \\
\hline \multicolumn{4}{|l|}{ Pre DOC Treatment } \\
\hline Yes & $61(32.4 \%)$ & $145(55.6 \%)$ & \multirow[t]{2}{*}{$<0.001$} \\
\hline No & $127(67.6 \%)$ & $116(44.4 \%)$ & \\
\hline \multicolumn{4}{|l|}{ ALP } \\
\hline$>274 \mathrm{IU} / \mathrm{L}$ & 92 (48.9\%) & $119(45.6 \%)$ & \multirow[t]{2}{*}{0.484} \\
\hline$\leq 274 \mathrm{IU} / \mathrm{L}$ & $96(51.1 \%)$ & $142(54.4 \%)$ & \\
\hline \multicolumn{4}{|l|}{ LDH } \\
\hline$>220 \mathrm{IU} / \mathrm{L}$ & $96(51.1 \%)$ & $122(46.7 \%)$ & \multirow[t]{2}{*}{0.366} \\
\hline$\leq 220 \mathrm{IU} / \mathrm{L}$ & 92 (48.9\%) & 139 (53.3\%) & \\
\hline
\end{tabular}

PSA Prostate-specific antigen, CRPC Castration-resistant prostate cancer, DOC Docetaxel $A B I$ Abiraterone, ENZ Enzalutamide, ALP Alkaline phosphatase, $L D H$ Lactate dehydrogenase 
This study was approved by the Institutional Review Board of Yokohama City University Medical Center (Yokohama, Japan) (IRB No. D1603004). Written informed consent was waived due to the retrospective observational nature of the study, and all methods complied with the Declaration of Helsinki.

\section{Assessment of the NLR}

The pretreatment NLR was calculated using the complete blood cell count (CBC). To exclude any effect on the NLR, cases with $\mathrm{C}$-reactive protein elevation or infection were excluded, as in our previous study [9]. Candidate cut-off points of the NLR were determined by the area under the receiver operator characteristic curve (AUROC).

\section{Prostate cancer progression and the NLR transition}

To examine the NLR transition in prostate cancer status, we compared our previous reports as follows (Table 2): 1) 811 patients whose PSA was 4 to $10 \mathrm{ng} / \mathrm{mL}$, including 357 localized prostate cancer and 453 pathological confirmed non-prostate cancer patients [3]; 2) 48 metastatic hormone-naïve prostate cancer (mHNPC) patients [7]; 3) 47 CRPC patients resistant to docetaxel and who received cabazitaxel chemotherapy [10]; and 4) this cohort, including 243 pre-docetaxel and 206 post-docetaxel patients.

\section{Statistical analyses}

The patients' characteristics and preoperative factors were analyzed by the Mann-Whitney $U$ and chi-square tests, using the Graph Pad Prism software program (Graph Pad Software, La Jolla, CA, USA). Candidate cutoff points were identified using the AUROC. We set the endpoint as death 3 years from ENZ/ABI installation. The candidate cut-off points were determined using Younden's index. The survival duration was defined as the time between the dates of initial ABI/ENZ installation and the time of death. A log-rank test was performed for comparisons between the higher and lower NLR groups. Univariate and multivariate analysis was performed to determine whether or not the NLR was an independent prognostic factor. Multivariate analysis was performed using the clinical important variables including ENZ vs $\mathrm{ABI}$, metastasis vs non-metastasis, Gleason score $\geqq 8$ vs $<8$, age, pre DOC treatment, NLR, ALP, and $\mathrm{LDH}$. We also performed multivariate analysis categorized and continuous values. $P$ values of $<0.05$ were considered to indicate statistical significance.

\section{Results}

A total of 805 CRPC patients received ABI or ENZ treatment, and 449 of them had available NLR data (Fig. 1). A total of 261 (58.1\%) cases underwent ENZ first, and 188 (41.9\%) underwent ABI first. Of these patients, 206 (45.9\%) received docetaxel chemotherapy for CRPC preoperatively. None of the patients received upfront docetaxel or upfront abiraterone therapy for hormone-naïve status. The median (mean $\pm \mathrm{SD}$ ) follow-up duration was $12.0(11.8 \pm 7.1)$ months.

There were no marked differences in the OS between the ABI and ENZ groups (23.3 vs. 23.0 months, $p=$ 0.411 ) (Fig. 2). The median NLR was 2.90 , and the ROC suggested a candidate cut-off point of 3.02 (Fig. 3). The median OS was 17.3 months in the higher NLR group $(\geq 3.02)$ and 27.3 months in the lower NLR group $(<$ 3.02) $(p<0.0001)$ (Fig. 4). This trend was also observed in the ABI and ENZ groups (ABI: 29.3 vs. 15.1 months, ENZ: not reached vs. 19.5 months, $p<0.0001$ and $<$ 0.0001, respectively) (Fig. 5). A multivariate analysis showed that a higher NLR (using the cut-off points based on the ROC), pre-docetaxel status, higher ALP (median value or more), and higher LDH (median value or more) were independent risk factors (Table 3). We also performed a multivariate analysis using continuous age, NLR, ALP, and LDH values and showed that the higher NLR, higher ALP, and higher LDH were independent risk factors for a poor prognosis (Supplementary Table 1).

The NLR value was found to be correlated with prostate cancer progression, gradually increasing as pathological non-adenocarcinoma with PSA 4 to $10 \mathrm{ng} / \mathrm{mL}$, pathological confirmed adenocarcinoma with PSA 4 to $10 \mathrm{ng} / \mathrm{mL}, \mathrm{mHNPC}$, pre-docetaxel CRPC, post-docetaxel CRPC, and docetaxel resistant pre-cabzitaxel patients. Interestingly, the NLR at the time of the PSA nadir was lower than mHSPC or CRPC status (Fig. 6).

\section{Discussion}

This study investigated the importance of the NLR as a prognostic factor for CRPC patients who receive firstline androgen replacement therapy (ART), including

Table 2 Summarize of pretreatment NLR in each prostate cancer status

\begin{tabular}{lll}
\hline Treatment & $\mathbf{n}$ & Journal \\
\hline Pre and post DOC treatment & 449 & Current Study \\
Pre CBZ treatment & 47 & Uemura and Kawahara et al. Biomed Res Int. 2017 \\
Initial metastatic prostate cancer & 48 & Kawahara and Yokomizo et al. BMC Cancer 2016 \\
PSA 4 to $10 \mathrm{ng} / \mathrm{mL}$ & 810 & Kawahara and Fukui et al. Oncotarget 2015 \\
\hline
\end{tabular}

DOC Docetaxel, CBZ Cabazitaxel, PSA Prostate-specific antigen 


\section{Patients' selection}

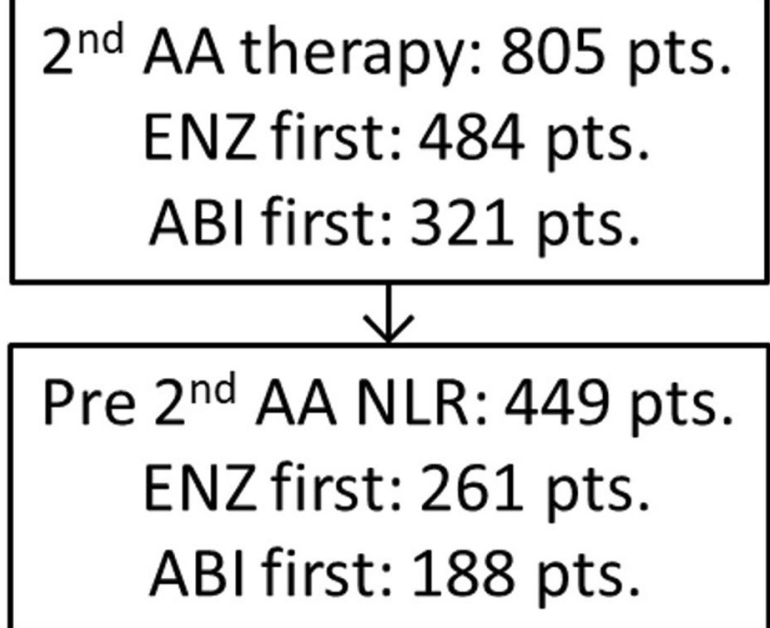

AA; antiandrogen, ABI; Abiraterone, ENZ; Enzalutamide

Fig. 1 Patient selection

ENZ or ABI. The NLR has been reported as a prognostic factor for several solid malignancies, including prostate cancer. Our previous reports showed that the NLR played important role as whether prostate cancer or not in patients with a serum PSA level of 4 to $10 \mathrm{ng} / \mathrm{mL}$, or as a prognostic factor in $\mathrm{mHNPC}[3,14]$. In the present study, we further evaluated the value of the NLR for predicting prostate cancer progression. The NLR was found to be correlated with prostate cancer progression as low value in PSA between 4 to 10 or prostate cancer patients received radical prostatectomy, or the situation the prostate cancer patients whose PSA were nadir after ADT [18]. In

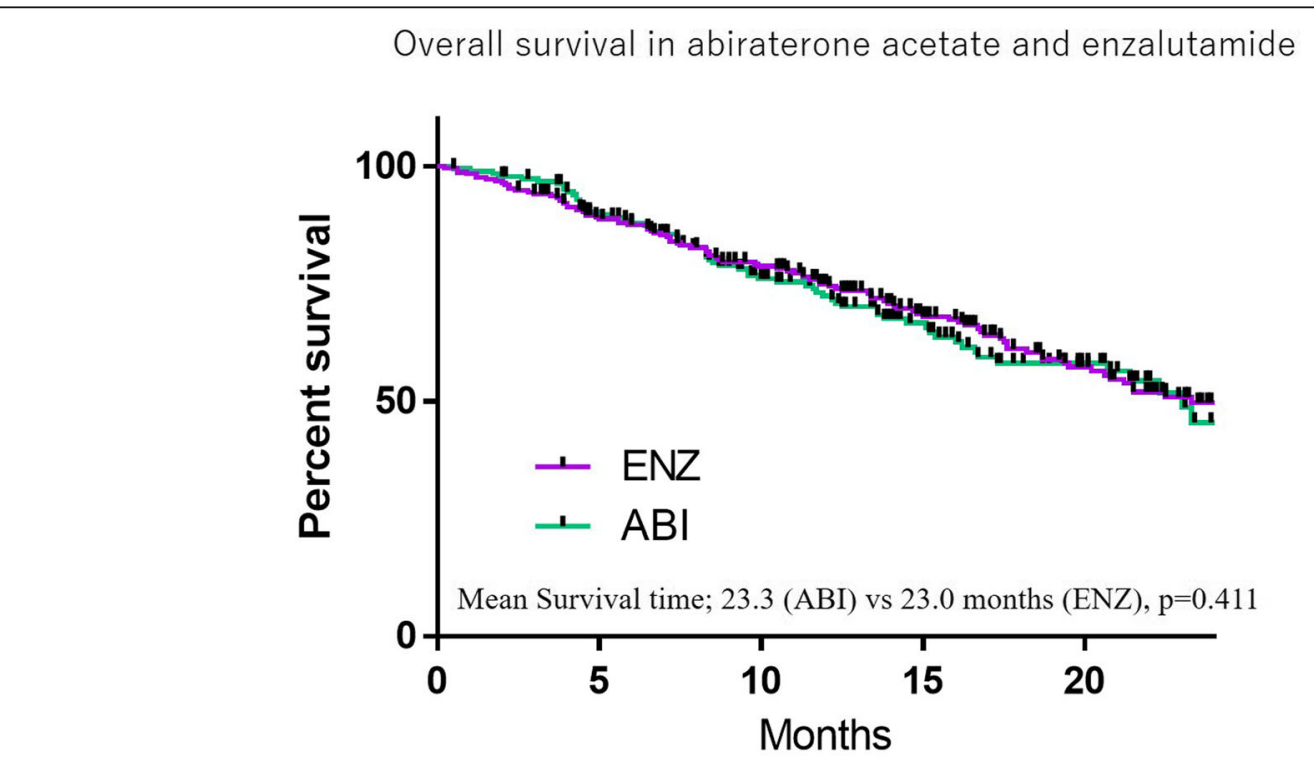

NLR; Neutrophil to lymphocyte ratio, ABI; Abiraterone, ENZ; Enzalutamide

Fig. 2 Receiver operator characteristic curve 


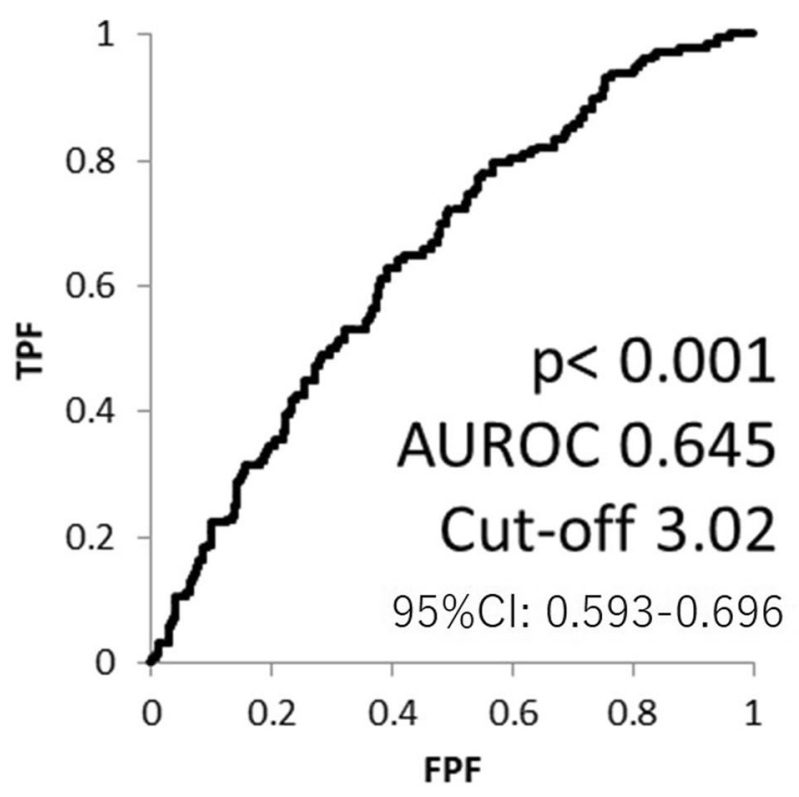

AUROC; Area under the curve of receiver operating characteristic TPF; True Positive Fraction, FPF; False Positive Fraction

Fig. 3 The overall survival in abiraterone acetate and enzalutamide

contrast, the NLR gradually increased in cases of predocetaxel CRPC as well as in patients with a post-docetaxel status. Based on these findings, the NLR might not be simply a prognostic factor but also a tumor-related marker reflecting prostate cancer aggressiveness.
The details concerning the mechanism underlying the association of the NLR and prostate cancer aggressiveness are unclear. Some inflammatory markers, including the NLR, MLR, total lymphocyte count (TLC), and psoas muscle index (PMI), have been reported to be poor prognostic markers in solid malignancies [1]. These

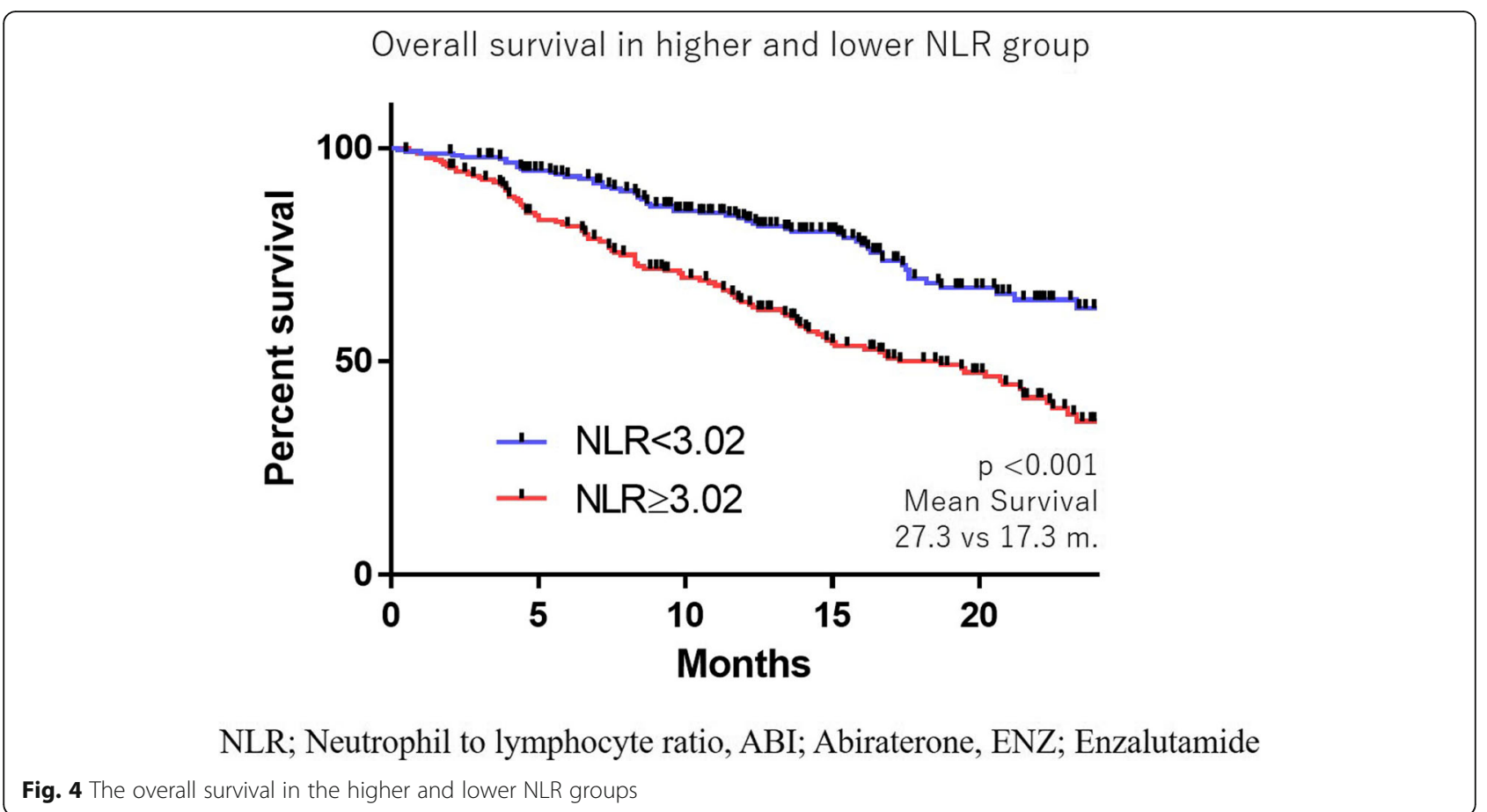


Overall survival in higher and lower NLR group who received

a) abiraterone acetate or b) enzalutamide

a)

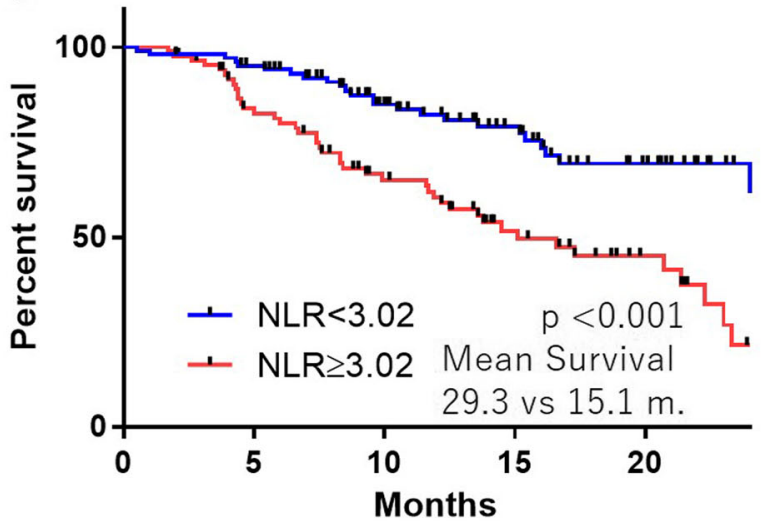

b)

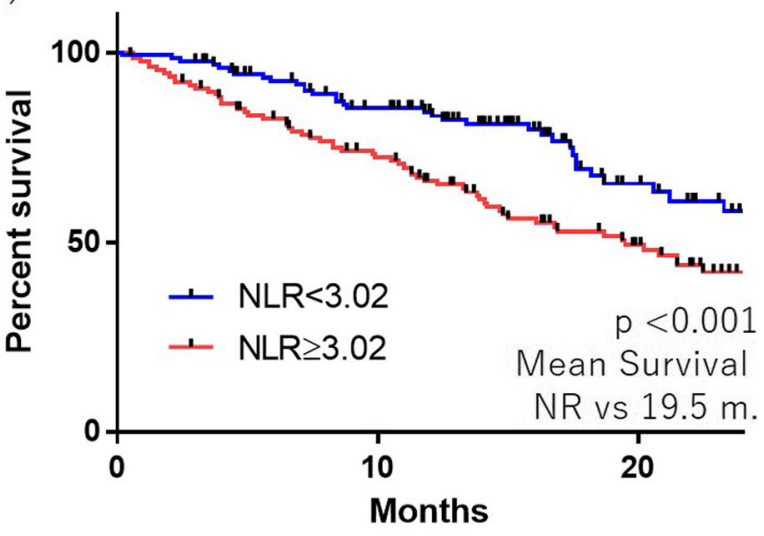

NLR; Neutrophil to lymphocyte ratio, ABI; Abiraterone, ENZ; Enzalutamide

Fig. 5 The overall survival in the higher and lower NLR groups who received a) abiraterone acetate or b) enzalutamide

markers are increased under conditions of a reduced lymphocyte count [19]. No marked differences were noted in the OS between the ABI and ENZ groups in our study. Kim et al. also found no marked differences in the OS for CRPC patients who used ENZ-ABI sequence or ABI-ENZ sequence [20]. Our study also showed similar results to real-world clinical practice. Tumor markers to predict the efficacy of ABI or ENZ are needed, but our results indicated that a high NLR was associated with a poor prognosis in both ABI and ENZ groups.

A previous study showed that the NLR was higher in cases of mHSPC than in localized prostate cancer, and its increase correlated with treatment resistance in cases of CRPC [7]. Furthermore, the NLR was decreased at the time of the PSA nadir. Most previous studies showed the NLR to be a prognostic factor, but the present study revealed a correlation between the NLR and prostate cancer progression [21-24]. The NLR might thus reflect the current prostate cancer aggressiveness.

Several limitations associated with the present study warrant mention. First, this was a retrospective observation study, and quite a few cases were excluded because pre-ABI or pre-ENZ CBCs had not been collected. However, despite this limitation, this was the first study to evaluate the pre-ABI/pre-ENZ NLR in a multicentral study. Second, this study did not reveal the mechanisms underlying the association between the NLR and prostate cancer progression. Further studies will be needed to confirm this point using the same patient cohort with continuous follow-up CBCs. Third, this study was

Table 3 Univariate and multivariate analyses of factors associated with overall survival

\begin{tabular}{|c|c|c|c|c|c|c|c|c|}
\hline \multirow[t]{3}{*}{ Variables } & \multicolumn{3}{|l|}{ Univariate } & \multicolumn{4}{|c|}{ Multivariate } & \multirow{3}{*}{$p$ value } \\
\hline & \multirow[t]{2}{*}{ HR } & \multicolumn{2}{|l|}{$95 \% \mathrm{Cl}$} & \multirow[t]{2}{*}{$p$ value } & \multirow[t]{2}{*}{ HR } & \multicolumn{2}{|l|}{$95 \% \mathrm{Cl}$} & \\
\hline & & Lower & Upper & & & Lower & Upper & \\
\hline ENZ vs $A B I$ & 1.280 & 0.873 & 1.884 & 0.205 & 1.105 & 0.810 & 1.507 & 0.529 \\
\hline Metastasis vs non-metastasis & 1.200 & 0.835 & 1.719 & 0.328 & 1.412 & 1.011 & 1.970 & 0.043 \\
\hline Gleason score $\geq 8$ vs Gleason score $<8$ & 0.810 & 0.566 & 1.148 & 0.232 & 1.004 & 0.731 & 1.379 & 0.981 \\
\hline Age $\geq 75.6$ (median) vs $<75.6$ & 1.100 & 0.770 & 1.571 & 0.601 & 0.988 & 0.729 & 1.338 & 0.938 \\
\hline DOC treatment vs non-DOC treatment & 2.070 & 1.410 & 3.045 & $<0.001$ & 2.160 & 1.571 & 2.970 & $<0.001$ \\
\hline NLR $>3.02$ vs $\leq 3.02$ & 2.070 & 1.094 & 2.300 & 0.015 & 2.115 & 1.540 & 2.906 & $<0.001$ \\
\hline ALP $>274$ (median) vs $\leq 274$ & 1.580 & 1.295 & 2.760 & $<0.001$ & 2.189 & 1.579 & 3.035 & $<0.001$ \\
\hline LDH $>220$ (median) vs $\leq 220$ & 1.790 & 1.234 & 2.597 & 0.002 & 2.284 & 1.647 & 3.168 & $<0.001$ \\
\hline
\end{tabular}

$H R$ Hazard ratio, CI Confidential interval, $A B I$ Abiraterone, ENZ Enzalutamide, DOC Docetaxel NLR Neutrophil to lymphocyte ratio, ALP Alkaline phosphatase, $L D H$ Lactate dehydrogenas 


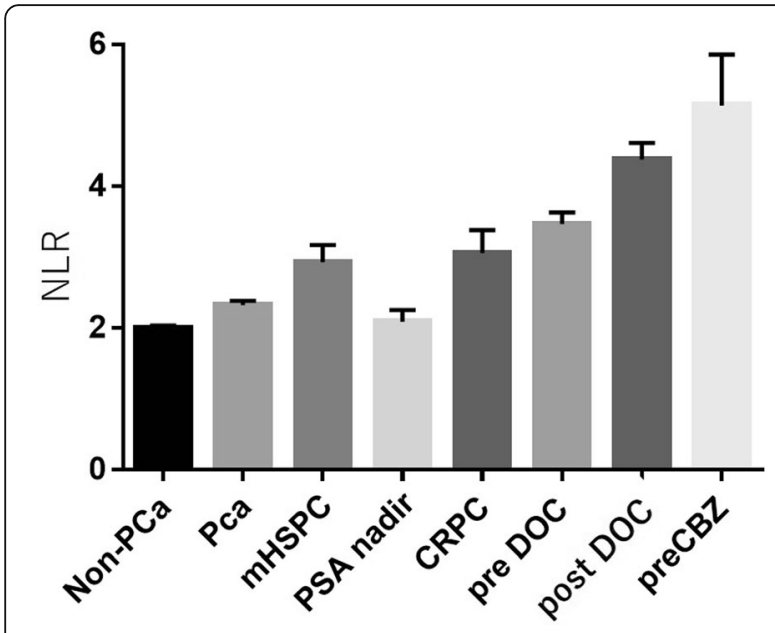

NLR; Neutrophil to lymphocyte ratio, Pca; Prostate cancer mHSPC: Metastatic hormone-sensitive prostate cancer PSA; Prostate-specific antigen, CRPC; Castration-resistant prostate cancer, DOC; Docetaxel, CBZ; Cabazitaxel

Fig. 6 The NLR changes by prostate cancer status. Mean +/- SEM

unable to determine the power of NLR as a prognostic factor for cancer progression. Both a high NLR using the cut-off point $(>3.02)$ and continuous number of NLR values were independent risk factors for a poor prognosis. On the other hand, the HR was differed using these different methods. And also we could not evaluated the power of poor prognosis comparing to the other previous reports. Further studies will be needed to determine good candidate cut-off points for daily clinical practice. The last one is that these data was obtained from each institutional data subsets. Thus, central testing is needed for future study to confirmed no differences between each institutions.

\section{Conclusion}

A higher NLR was associated with a poor OS in CRPC patients who received ABI or ENZ. The NLR was positively correlated with prostate cancer progression.

\section{Supplementary information}

Supplementary information accompanies this paper at https://doi.org/10. 1186/s12885-020-07410-2.

Additional file 1.

\section{Abbreviations}

NLR: neutrophil-to-lymphocyte ratio; CRPC: castration-resistant prostate cancer; ABI: abiraterone acetate; ENZ: enzalutamide; OS: overall survival; MNLR: monocyte-lymphocyte ratio; $\mathrm{MHSPC}$ : metastatic hormone-sensitive prostate cancer; CBC: complete blood cell count; AUROC: area under the receiver operator characteristic curve

\section{Acknowledgements}

We would like to thank Japan Medical Communication for performing the English language editing of this manuscript.

\section{Authors' contributions}

TK, YM are responsible for the concept and drafted the manuscript. TK, YM drafted the manuscript. MK, $\mathrm{KT}, \mathrm{IK}, \mathrm{HY}, \mathrm{OK}, \mathrm{HT}, \mathrm{MI}, \mathrm{HU}$ helped to gather the patient information. MK, $\mathrm{KT}, \mathrm{IK}, \mathrm{HY}, \mathrm{OK}, \mathrm{HT}, \mathrm{Ml}, \mathrm{HU}$ and $\mathrm{MY}$ provided the intellectual content and critically reviewed the manuscript. All authors have read and approved the final manuscript.

\section{Funding}

The present study was not supported by any funding.

\section{Availability of data and materials}

Due to ethical restrictions, the raw data underlying this paper is available upon request from the corresponding author.

\section{Ethics approval and consent to participate}

This study was carried out in compliance with the Declaration of Helsinki and was approved by the Institutional Review Board of each institution (D1603004). Informed consent to participate in the study were obtained from all subjects by opt-out style in Yokohama City University Medical Center (Yokohama, JAPAN)

\section{Consent for publication}

This study was approved by the Institutional Review Board of Yokohama City University Medical Center (Yokohama, Japan) (IRB No. D1603004) including the permission to publish. Written informed consent was waived due to the retrospective observational nature of the study, and all methods complied with the Declaration of Helsinki.

\section{Competing interests}

The authors declare no conflicts of interest in association with the present study.

\section{Author details}

${ }^{1}$ Departments of Urology and Renal Transplantation, Yokohama City University Medical Center, Yokohama 2320024, Japan. ${ }^{2}$ Department of Urology, Nagoya University, Nagoya 4668560, Japan. ${ }^{3}$ Department of Urology, Kitasato University School of Medicine, Sagamihara 2520375, Japan.

Received: 17 May 2020 Accepted: 14 September 2020

Published online: 25 September 2020

\section{References}

1. Ohno Y. Role of systemic inflammatory response markers in urological malignancy. Int J Urol. 2019:26(1):31-47.

2. Mochizuki T, Kawahara T, Takamoto D, Makiyama K, Hattori Y, Teranishi II, Miyoshi Y, Yumura Y, Yao M, Uemura H. The neutrophil-to-lymphocyte ratio (NLR) predicts adrenocortical carcinoma and is correlated with the prognosis. BMC Urol. 2017;17(1):49.

3. Kawahara T, Fukui S, Sakamaki K, Ito Y, Ito H, Kobayashi N, Izumi K, Yokomizo Y, Miyoshi Y, Makiyama K, et al. Neutrophil-to-lymphocyte ratio predicts prostatic carcinoma in men undergoing needle biopsy. Oncotarget. 2015;6(31):32169-76

4. Kumano $Y$, , Hasegawa $Y$, Kawahara T, Yasui M, Miyoshi Y, Matsubara N, Uemura $H$. Pretreatment neutrophil to lymphocyte ratio (NLR) predicts prognosis for castration resistant prostate Cancer patients underwent Enzalutamide. Biomed Res Int. 2019;2019:9450838.

5. Yasui M, Hasegawa Y, Kawahara T, Kumano Y, Miyoshi Y, Matsubara N, Uemura $\mathrm{H}$. Baseline neutrophil-to-lymphocyte ratio predicts the prognosis of castration-resistant prostate cancer treated with abiraterone acetate. Mol Clin Oncol. 2018:8(4):592-4.

6. Tatenuma T, Kawahara T, Hayashi N, Hasumi H, Makiyama K, Nakaigawa N, Kishida T, Miyoshi Y, Yao M, Uemura H. The Pretherapeutic neutrophil-tolymphocyte ratio for Docetaxel-based chemotherapy is useful for predicting the prognosis of Japanese patients with castration-resistant prostate Cancer. Biomed Res Int. 2019;2019:2535270

7. Kawahara T, Yokomizo Y, Ito $Y$, Ito H, Ishiguro H, Teranishi J, Makiyama K, Miyoshi Y, Miyamoto $\mathrm{H}$, Yao M, et al. Pretreatment neutrophil-to- 
lymphocyte ratio predicts the prognosis in patients with metastatic prostate cancer. BMC Cancer. 2016;16:111.

8. Kasuga J, Kawahara T, Takamoto D, Fukui S, Tokita T, Tadenuma T, Narahara M, Fusayasu S, Terao H, Izumi K, et al. Increased neutrophil-to-lymphocyte ratio is associated with disease-specific mortality in patients with penile cancer. BMC Cancer. 2016;16:396.

9. Kawahara T, Furuya K, Nakamura M, Sakamaki K, Osaka K, Ito H, Ito Y, Izumi K, Ohtake S, Miyoshi Y, et al. Neutrophil-to-lymphocyte ratio is a prognostic marker in bladder cancer patients after radical cystectomy. BMC Cancer. 2016;16:185.

10. Uemura K, Kawahara T, Yamashita D, Jikuya R, Abe K, Tatenuma T, Yokomizo Y, Izumi K, Teranishi Jl, Makiyama K, et al. Neutrophil-to-lymphocyte ratio predicts prognosis in castration-resistant prostate Cancer patients who received Cabazitaxel chemotherapy. Biomed Res Int. 2017;2017:7538647.

11. Maeda Y, Kawahara T, Koizumi M, Ito H, Kumano Y, Ohtaka M, Kondo T, Mochizuki T, Hattori Y, Teranishi J, et al. Lack of an association between neutrophil-to-lymphocyte ratio and PSA failure of prostate Cancer patients who underwent radical prostatectomy. Biomed Res Int. 2016;2016:6197353.

12. Ryan CJ, Smith MR, de Bono JS, Molina A, Logothetis CJ, de Souza P, Fizazi $\mathrm{K}$, Mainwaring P, Piulats $\mathrm{JM}, \mathrm{Ng} \mathrm{S}$, et al. Abiraterone in metastatic prostate cancer without previous chemotherapy. N Engl J Med. 2013;368(2):138-48.

13. Scher HI, Fizazi K, Saad F, Taplin ME, Sternberg CN, Miller K, de Wit R, Mulders P, Chi KN, Shore ND, et al. Increased survival with enzalutamide in prostate cancer after chemotherapy. N Engl J Med. 2012;367(13):1187-97.

14. Ninomiya S, Kawahara T, Tatenuma T, Miyoshi Y, Miyamoto H, Yao M, Uemura H. Preference for enzalutamide capsules versus tablet pills in patients with prostate cancer. Int J Urol. 2019;26(12):1161-2.

15. Bilusic M, Madan RA, Gulley JL. Immunotherapy of prostate Cancer: facts and hopes. Clin Cancer Res. 2017;23(22):6764-70.

16. Ku SY, Gleave ME, Beltran H. Towards precision oncology in advanced prostate cancer. Nat Rev Urol. 2019;16(11):645-54.

17. Spreafico A, Chi KN, Sridhar SS, Smith DC, Carducci MA, Kavsak P, Wong TS, Wang L, Ivy SP, Mukherjee SD, et al. A randomized phase II study of cediranib alone versus cediranib in combination with dasatinib in docetaxel resistant, castration resistant prostate cancer patients. Investig New Drugs. 2014;32(5):1005-16.

18. Genta Iwamoto TK, Uemura H. The neutrophil-to-lymphocyte ratio at the prostate-specific antigen nadir predicts the time to castration-resistant prostate cancer. Asian J Urol. 2020; In press.

19. Susumu Umemoto GN, Tsutsumi S, Kobayashi K, Ousaka K, Kishida T. Predictive and prognostic significance of pre-treatment lymphocyte count in patients with metastatic urothelial carcinoma treated with platinumbased first-line chemotherapy. Jpn J Urol. 2019;110(3):160-7.

20. Khalaf DJ, Annala M, Taavitsainen S, Finch DL, Oja C, Vergidis J, Zulfiqar M, Sunderland K, Azad AA, Kollmannsberger CK, et al. Optimal sequencing of enzalutamide and abiraterone acetate plus prednisone in metastatic castration-resistant prostate cancer: a multicentre, randomised, open-label, phase 2, crossover trial. Lancet Oncol. 2019;20(12):1730-9.

21. Diem S, Schmid S, Krapf M, Flatz L, Born D, Jochum W, Templeton AJ, Fruh M. Neutrophil-to-lymphocyte ratio (NLR) and platelet-to-lymphocyte ratio (PLR) as prognostic markers in patients with non-small cell lung cancer (NSCLC) treated with nivolumab. Lung Cancer. 2017;111:176-81.

22. Asaoka T, Miyamoto A, Maeda S, Tsujie M, Hama N, Yamamoto K, Miyake M, Haraguchi N, Nishikawa K, Hirao M, et al. Prognostic impact of preoperative NLR and CA19-9 in pancreatic cancer. Pancreatology. 2016;16(3):434-40.

23. Onal C, Sedef AM, Kose F, Oymak E, Guler OC, Sumbul AT, Aksoy S, Akkus Yildirim B, Besen AA, Muallaoglu S, et al. The hematologic parameters in metastatic castration-resistant prostate cancer patients treated with abiraterone acetate. Future Oncol. 2019:15(13):1469-79.

24. Lorente D, Mateo J, Templeton AJ, Zafeiriou Z, Bianchini D, Ferraldeschi R, Bahl A, Shen L, Su Z, Sartor O, et al. Baseline neutrophil-lymphocyte ratio (NLR) is associated with survival and response to treatment with secondline chemotherapy for advanced prostate cancer independent of baseline steroid use. Ann Oncol. 2015;26(4):750-5.

\section{Publisher's Note}

Springer Nature remains neutral with regard to jurisdictional claims in published maps and institutional affiliations.

\section{Ready to submit your research? Choose BMC and benefit from}

- fast, convenient online submission

- thorough peer review by experienced researchers in your field

- rapid publication on acceptance

- support for research data, including large and complex data types

- gold Open Access which fosters wider collaboration and increased citations

- maximum visibility for your research: over $100 \mathrm{M}$ website views per year

At $\mathrm{BMC}$, research is always in progress.

Learn more biomedcentral.com/submissions 